\title{
Consumers' Perception of Artificial Intelligence in Banking Sector
}

\author{
Marina Ryzhkova ${ }^{1,2 *}$, Ekaterina Soboleva ${ }^{1}$, Anastasia Sazonova ${ }^{1}$, and Mikhail Chikov ${ }^{1}$ \\ ${ }^{1}$ National Research Tomsk State University, 36 Lenin Avenue, 634050, Tomsk, Russia \\ ${ }^{2}$ National Research Tomsk Polytechnic University, 30 Lenin Avenue, 634050, Tomsk, Russia
}

\begin{abstract}
In the article, we analyze the impact of artificial intelligence (AI) on banking development. Banks implement AI to provide digital assistance and financial advice to clients, measure their financial standing etc. The paper also includes cases of the AI solutions marketing and some ideas of brand-new banking AI-based services. Despite the rapid spreading of AI across the different spheres, its efficiency is based, primarily, on consumers attitude and loyalty to this technology. Our research shows that Russian business and consumers perceive AI in a positive light. Sberbank specialists have a positive attitude to the AI implementation in their work, consider these solutions as assistance in performing routine operations and are not afraid of dismissals. They use AI solutions both at work and in everyday life. The emerging fears are associated with possible technical failure, unauthorized transmission of personal data, lack of privacy, and unexpected consequences of AI implementation. However, in general, experts understand that the future of the financial sector is connected with this technology. According to Sberbank employees, consumers tend to demonstrate a certain level of mistrust to AI, which could result from misunderstanding of how this technology works, and what impact it has on their ways of life. Meanwhile, the level of AI resistance from both sides decreases with time. Therefore, state and financial mediators could create necessary conditions for banking development based on modern technologies.
\end{abstract}

Keywords: artificial intelligence, banking, resistance to digitalization.

\section{Introduction}

In the last decade, the financial sector has undergone enormous changes along with other economic areas influenced by modern technologies. Big data \& business analytics, VR/AR, blockchain, biometrics, and AI are key drivers of digital transformation in the financial institutional environment.

The most significant changes have taken place in banking. It has faced with fierce competition caused by implementation of digital technologies. Nowadays, traditional banks

*Corresponding author: marybox@inbox.ru 
have to compete against non-banking rivals entered the financial arena. These companies are positioned as neobanks. It implies that they perform traditional banking tasks (opening accounts, lending, borrowing etc.) exclusively based on on-line technologies (for instance, Tinkoff Bank, Talkbank). Megaservices GAFA (Google, Apple, Facebook, Amazon), Chinese leaders (Alibaba, Baidu) foray into financial areas [1]. They create unique consumer experience and expect clients to stay in contact for a long period.

Trying to win a competition, traditional banks have chosen digital transformation to meet the clients' needs under the conditions of a permanently changing environment. To save their market share banks implement new financial technologies, provide maximum customization and personalization, gives consumer support 24/7, and try to follow the clients journey during the life cycle [2]. Banks develop financial ecosystems based on digital platforms where consumers could find a variety of services - from marketplace and online payment to lifestyle and education [3].

Digital technologies transform core principles of interaction between banks and clients, financial mediators and regulators. They change forms of services provision. Banks are expected to increase digital services, while traditional solutions become progressively infrequent.

\section{Installation of $\mathrm{Al}$ in banking}

$\mathrm{AI}$ is highly demanded in banking. More and more banks make decisions to implement this technology into their business processes from face detection and speech recognition to determining customer behavior [4]. Banks along with the other financial and non-financial companies exploit advantages of AI and cognitive technologies. Therefore, they invest heavily in these technological solutions. According to IDC, Russian investment in AI reach $\$ 172,5$ million in 2019, whereas in Europe AI spending attains the level of \$7 billon [5].

Spendings on server infrastructures for AI was the largest category in total AI investment (48\%), followed by IT-services (24\%), and AI-software (14\%). The share of investment in data storage system was relatively low - only $6 \%$. It is slightly more than spendings on AIplatform and business services (4\%). The industries with the largest investment in AI are financial sector, discrete manufacturing, and retail. In total these three industries are responsible for almost $70 \%$ of all AI spendings [4].

We expect the upward trend towards the implementation of AI in banking. AI algorithms and cognitive technologies enable banks to be proactive and rise to a new level of communications with clients, creating personalized offerings.

According to RAEX [6], leading banks have adapted AI platforms to their needs, built strong teams of experts, organized data processing, and gained experience in using advanced processing techniques. Based on the survey of AI and machine learning in banking, Russian banks were divided into three groups (Table 1).

Table 1. Classification of Russian banks by implementing AI and machine learning [6].

\begin{tabular}{|c|c|c|}
\hline Level & $\begin{array}{c}\text { Declared level of AI } \\
\text { and machine learning } \\
\text { implementation ... }\end{array}$ & Examples \\
\hline Advanced & $\begin{array}{c}\text { far exceeds the } \\
\text { intermediate level }\end{array}$ & $\begin{array}{c}\text { Tinkoff Bank, } \\
\text { Gazprombank, MTS Bank }\end{array}$ \\
\hline Upper & $\begin{array}{c}\text { exceeds the } \\
\text { intermediate level, } \\
\text { banks have high } \\
\text { intermediate }\end{array}$ & $\begin{array}{c}\text { Credit Bank of Moscow, } \\
\text { Russian Standard Bank, } \\
\text { PSBank, Renaissance } \\
\text { Credit in this sphere }\end{array}$ \\
\hline Intermediate & $\begin{array}{c}\text { corresponds to } \\
\text { intermediate level }\end{array}$ & $\begin{array}{c}\text { BCSBank, Delta Credit } \\
\text { Bank, Bank Otkritie }\end{array}$ \\
\hline
\end{tabular}


Thus, AI become an effective means by which banks compete with each other. Usually, they use it for credit scoring; however, AI goes beyond the creditworthiness measurement.

The core principle of modern banking is to assist clients with their goals achievement. Combined with IT-companies, banks improve quality of service, make it more personalized. For instance, Pixoneye has created technological solution that enables to recognize clients needs based on their photos in social networks. Gridspase is specialized in analysis of speech patterns. This service allows identifying clients' mood, so a bank clerk could correct the conversation scenario. Curve and Mastercard have made an app binding all client's credit and debit cards to optimize payments and manage expenses [7].

Robo-advising is another important area where AI plays a key role. This service is considered as an alternative to financial consultants. It is attractive to both banks and clients due to access to actual information, ease of account opening and transactions processing. Clients could mainly benefit from robo-advising in online-trading and offering personalized investment portfolio, based on available capital, desired level of risk and rate of return [8]. In Russia these services are offered by Sberbank (Easy Investment), Yandex (Yammi), and Rosbank (SmartInvest) [9].

Citibank use AI to create analytical platform for data storing in real time. It allows knowing the clients ' needs, understanding their behavior and improving quality of service. British Starling Bank has developed a digital platform based on application programming interface (API) to identify the place of purchase and link it with customer loyalty program [7].

Banks emphasize a role of AI and cognitive technologies in rising to major challenges. For example, Sberbank uses AI to reduce employee turnover. AI evaluates the mood of applicants and assigns them a score to decide whether the applicant will stay at the given position not for a long time. Interestingly, AI uses only the information provided by the applicant or bank itself (in case, the applicant is a client of the bank). Nowadays, this technology is applied to hiring financial advisors; however, Sberbank is going to implement it in the whole recruitment process. Compared to 2018, the number of employees decreased by 8000 down to 299700 in 2019, while the cost of employing the staff increased by $7.4 \%$ and reached 205.4 billion rubles. Nevertheless, the bank strives to reduce personnel annually. In May 2020, only 281 thousand employees were left to work at Sberbank. The target for 2025 is 165 thousand employees [10].

Other problems, which the banks face, are financial fraud and money laundering. For instance, US Bank collects information about clients and their transactions and detects patterns of misbehavior based on machine learning. Tinkoff Bank takes a similar approach to cybersecurity. Machine learning and predictive models are key elements of eyeDES platform. This technology enables to analyze data anomalies and outliers and identify fraudulent activity. It allows banks to detect already known as well as completely new types of fraud. EyeDES is an example of explainable AI. It implies that obtaining results and models could be easily understood by natural intelligence [11].

Explainable AI is seen as a bridge to trust in modern technologies. Users tend to mistrust AI when they do not understand what is going on 'under the hood', or in other words, when the foundations of decision making are extremely complicated, because choices are made by neural networks [12].

Thus, AI has become an essential part of daily banking routine. It allows banks to

- computerize business processes, so that employees could concentrate on solving complex problems and perform creative tasks;

- meet the clients` needs in real time, offer personalized services and provide high quality customer support;

- reduce risk and improve resource allocation;

- increase competitiveness through collaboration with high-tech business. 


\subsection{Formatting the text}

The text of your paper should be formatted as follows:

- 10-point Times, Times Roman or Times New Roman.

- The text should be set to single line spacing.

- Paragraphs should be justified.

- The first paragraph after a section or subsection should not be indented; subsequent paragraphs should be indented by $5 \mathrm{~mm}$.

The use of sections to divide the text of the paper is optional and left as a decision for the author. Where the author wishes to divide the paper into sections the formatting shown in Table 2 should be used.

\section{Al perception: trends and challenges}

Although AI has a potential to be widely implemented in business processes, its performance depends on perception and loyalty demonstrated by consumers and business. It is believed that incomplete or distorted information could lead to miscomprehension of $\mathrm{AI}$ and negative attitude towards it.

Numerous studies show that business community is aware of AI benefits better than it is commonly believed. However, they agree that there are serious obstacle to AI implementation.

According to the Russian Public Opinion Research Center (VTsIOM) in 2019, $91 \%$ of firms knew about AI technology, $31 \%$ had already implemented it in one guise or another. $23 \%$ respondents considered the opportunity to adopt the AI. However, $43 \%$ did not plan to use it. The reasons why firms rejected this technology were connected with the lack of necessary resources and resistance to change [13].

IDC (International Data Corporation) [4] came to the same conclusion that nearly a third of Russian companies used AI software. The others were going to bring in cognitive technologies over the next two years. The major barriers to AI implementation are shown in Fig.1.

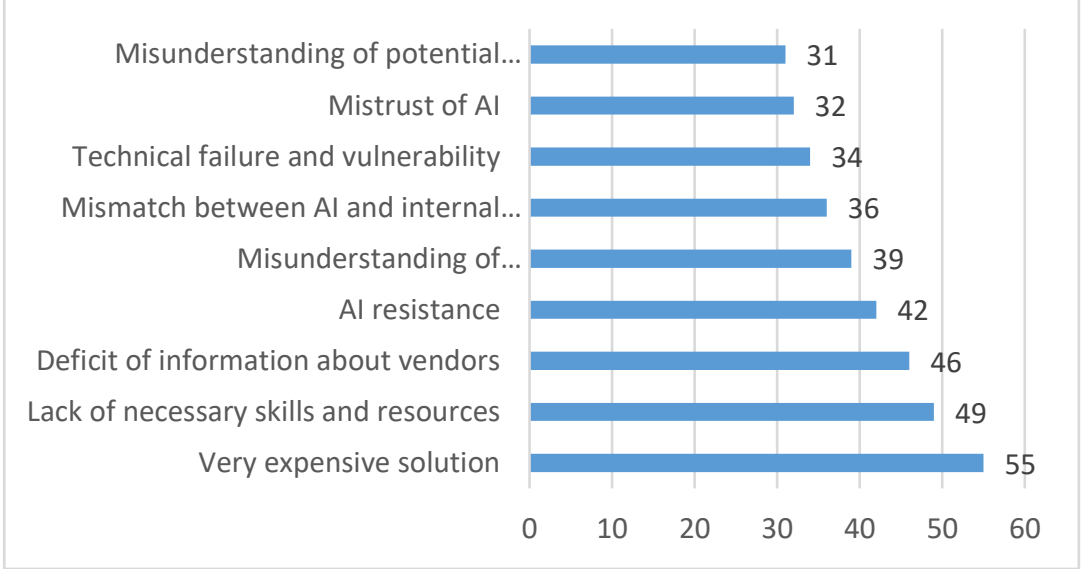

Fig. 1. Major barriers to AI implementation [4].

$55 \%$ of surveyed firms officials said that they did not use AI due to high initial investments. Nearly half of the companies (49\%) suffered from the shortage of necessary skills and qualified personnel. The possible decision in this situation is box solutions provided by IT industry. However, $46 \%$ of respondents confirmed that they did not have enough information about existing software vendors and their products in the area of AI. 
Consumers perceive AI in different ways. The results obtained by NMS Market Research showed that although $96 \%$ of Russians knew the term AI, they were not confident about its exact meaning [14]. This finding corresponds to the VTsIOM research which found out that $75 \%$ of respondents heard about AI, but only $29 \%$ were able to define this term, and $38 \%$ knew the purposes AI could apply for. Nearly half of surveyed (48\%) found an interest in AI, $31 \%$ remains neutral, and $12 \%$ thought that AI could poses a threat [15].

Among those threats connected with AI, the respondents mentioned job slashing, possible cyberattack, personal data leakage, adverse effect on communication with other people, and technical imperfection. In comparison with the post-soviet countries, Russia has a bigger share of people who have positive attitude towards AI (Fig. 2). Probably, it is due to rapid growth in IT industry.

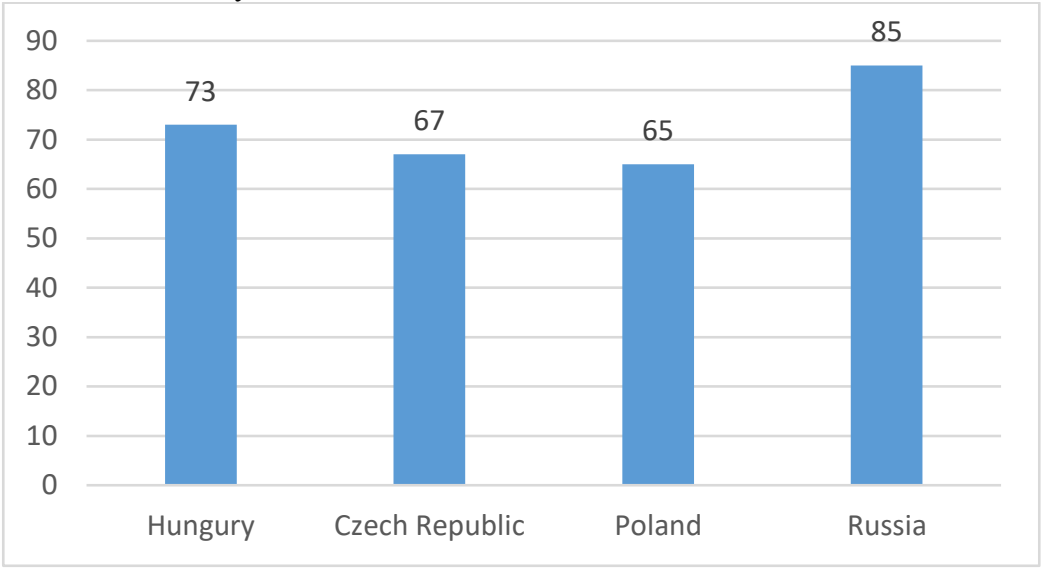

Fig. 2. Positive attitude towards AI [14].

The vast majority of Russians expect that AI will spread across different spheres - from workplace to daily routine. $68 \%$ of consumers welcome public services based on AI, nearly $50 \%$ are ready to use this technology for entertainment, healthcare, and education.

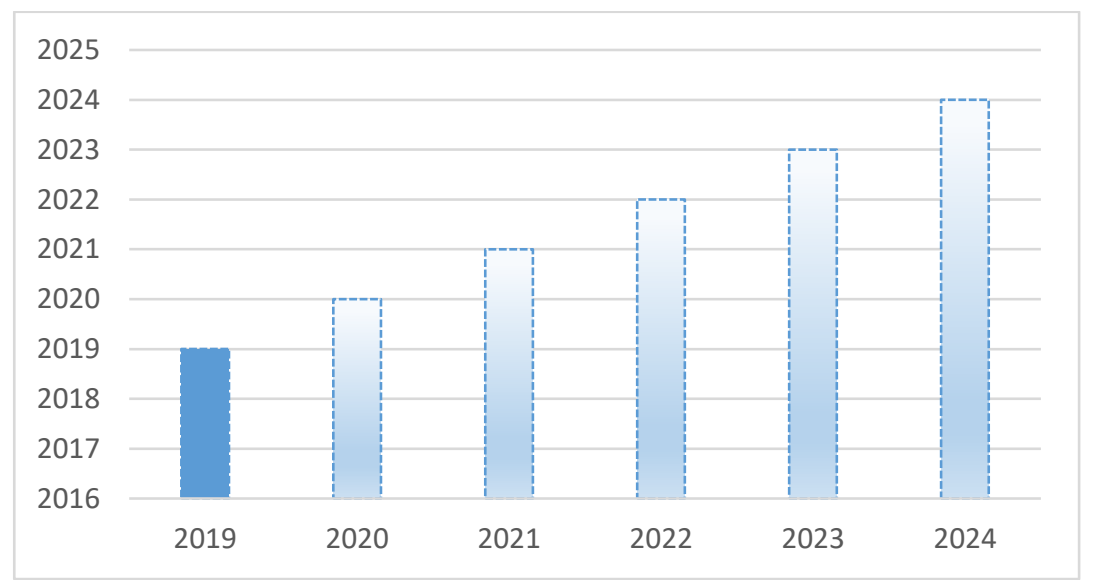

Fig. 3. Actual (2019) and forecast (2020-2024) returns on AI investment [15].

It is worthwhile to say that Sberbank leads the field as the top innovative bank. It spent about 47 billions of rubles for AI research and development. In 2019, Sberbank got a return of 42 billions of rubles on AI investment. This year, AI investment income is expected to reach 60 billions of rubles. 


\section{How Sberbank specialists perceive Al solutions?}

To prove these results on micro level, we conducted a survey of Sberbank employees. It was aimed at assessment of the attitude towards AI and changes it brought.

The survey was conducted in May 2020 in the central office of Sberbank in the city of Tomsk (Siberia, Russia). Seven managers and one deputy head of the Sales Managers department along with the expert from the Personnel Selection and Adaptation Department took part in the an anonymous questionnaire, which contained 19 both open and closed questions. The age of participants varied from 18 to 44 years, and work experience - from 3 months to 17 years.

Most of the respondents $(67 \%)$ were open to the idea of AI, the other part of survey participants welcomes the implementation of this technology in their daily routine. More than the half of the participants knew what types of AI services Sberbank uses, and also encountered AI and its technologies both at work and at everyday life when consuming services of various companies-AI adopters $(88 \%)$, the rest know about services, but have encountered only at work ( $22 \%)$. Often, the use of this technology was mentioned in connection with Sberbank Online mobile application and the voice assistant in customer support. According to the results of the survey, all respondents used at least one from four AI-based apps (voice assistants, chat bots, robotic advising, Sberbank Online mobile application), while all of them mentioned that they got used to the Sberbank Online mobile application. Nevertheless, at the same time, some respondents were not aware that Sberbank introduced artificial intelligence in 2019 to personalize Sberbank Online app. In addition, almost no one, except one person, knew what robo-advising is, thus we assume that AI investment advisers did not play an important role in Sberbank services yet. Similar research in India revealed that age and gender have no influence on AI awareness, whereas education and expertise play a key role in it [17].

With the AI implementation Sberbank increased the speed of service (seven employees confirmed that fact), and reduced the time for routine operations (according to the six employees), but only five people indicated that their working capacity improved, and only one person mentioned that in order to keep up with the requirements she had to undergo retraining. AI-based services did not affect the job performance of two employees. This could be explained by the lack of experience. Before they joined Sberbank, they had had no contact with AI.

Therefore, excluding two people who came relatively recently (3-5 months) and have not found any automation of the processes yet, over half of the employees used AI for counseling, information retrieval, and routine operations.

When we asked participants about problems with AI that have arisen or might arise over half gave their examples of possible problems, the rest found it difficult to answer. The key problems are connected with technical failures, inoperability and errors in the software or in the system. Therefore, clients spent time waiting or were offered wrong product due to incorrect processing of information. Another important issue pointed out by one of the employees was a lack of readiness for change. Indeed, the implementation of AI and, in general, innovations into the daily routine causes a storm of emotions and rejection, since a person does not have a clear idea of this technology. Therefore, there is no negative attitude to changing conditions, as well as conflicts in the future. It is necessary to position AI "to help", and not "replace" an employee. So, confidence will increase and employees will gradually get used to AI, finding some convenience from using AI for themselves.

Over half of the respondents said that AI technologies were unconditionally effective to solve certain problems of their company. The rest indicated that AI was more or less effective. At the same time, one employee found it difficult to answer, since he believes that the effectiveness depends on tasks AI was applied for. She added the example of other users from 
another bank who had difficulties but the participant herself did not encounter this either in work or in the personal use of services. For example, a chatbot gave information at a client's request with the word "balance", ignoring the context. As a result, the client had to rephrase the question so that the system transferred it to the operator. It was noted that system update could help to avoid these deficiencies.

In addition, we investigate the reaction of customers to the AI implementation in Sberbank and forms of reaction. Thus, three people replied that clients were open to the idea of AI, two people said that they were very satisfied, and one of them indicated that customers felt diffidence keeping in touch with AI for the first time. At the same time, two employees were undecided about the clients` attitude. Although one of them commented that, over half of people regarded AI as an ambiguous phenomenon, because it is difficult for people to get used to the new things. The other two participants chose the answer "other", where they wrote:

- «There are different categories of clients ("advanced") who enjoy using AI, and some do not»

- «Not everyone liked the voice assistant»

As to the form in which clients react to the use of artificial intelligence, the most popular were options «Leaving positive comments», «Taking for granted» and «Finding it difficult to answer». The remaining three people chose the answer "other", where they wrote:

- «It depends on the category of customers»

- «Leave both positive comments and negative reviews»

- « Often express any complaints orally, if any»

Thus, it can be concluded that people tend to be rather positive than negative towards the AI in Sberbank. However, the forms of customer reaction to AI services need to be investigated more precisely.

Five respondents replied that they reduced the number of meetings with offline clients. For one-third of surveyed that reduction was significant: they keep the number of meetings to a minimum.

The question about the most preferable sphere of using AI in Sberbank caused many difficulties. Since two people assumed that it was widely implemented and used by almost all departments, so they wrote the answer "in all". Another two respondents did not give an answer. The remaining five employees wrote, for instance:

- «In departments for work with private customers and firms, possibly in all»

- «In future departments to be created»

- «In client offices»

- «In the payment departments where customer service takes place directly»

- «Customer service, back offices»

Thus, they mainly cited examples of departments or offices related to customer service. They note that AI implementation will not only increase the efficiency of the company, but also improve the service provided to consumers.

The employees worried about computer malfunctions / technical problems (noted by seven respondents). They doubted that AI could effectively react to abnormal situations. At the same time, the possibility of hacking is high, since technologies are permanently being improved and cybercrimes are becoming more serious. The increased efficiency of AI-based systems perceived as a threat. On the one hand, employees worried about job slashing. On the other hand, they were ready to compete against AI, because its failure tolerance remained low.

All respondents believed that the state should contribute to the development of AI technologies, primarily due to the introduction of AI technologies in various spheres of human life (noted by eight respondents) and seven people indicated the need of support for retraining programs. 
In general, the attitude of Sberbank employees towards AI technologies was positive, they did not express any concerns about the implementation of AI, they perceive the process as an evolutionary development of science and technology.

\section{Conclusion}

Summing up, we can conclude that the majority of employees can express a definition of artificial intelligence, although it is not clear sometimes. At the same time, they are open to the idea of AI, since it is possible that they often encounter services using AI both at work and at everyday life. Also, participants are aware of various options for using AI in Sberbank (mobile application and voice assistants). The employees themselves often use mobile apps and chatbots.

At the same time, workers note that AI enable to increase the speed of service and reduce time for routine operations. In addition, employees did not encounter any problems after using AI, however, they noted possible difficulties such as technical failures, errors, and a lack of readiness for changes. In our opinion, the latter is important, since top managers of leading companies note that it is often difficult for employees to work together under the conditions of business transformation. Numerous studies of AI implementation come to this conclusion. Indeed, employees experience pressure and perceive AI as a threat, but after a period of adaptation, they could benefit from new technology and improve their job performance. Considering this, we conclude that AI technologies could solving problems effectively. However, innovative technologies are still imperfect, so there is constant need to improve the technologies for eliminating shortcomings.

Based on conducted survey, we found out that a majority of people tends to be rather positive than negative towards AI in Sberbank. However, the forms of customer reaction to AI services need to be investigated more precisely. Our investigation confirmed the increase in bank employee productivity, caused by AI implementation.

The reported study was funded by RFBR according to the research project № 19-010-00352: Scenarios of overcoming the consumer digitalization resistance on digital platforms market.

\section{References}

1. T. Carpenter, Revolutionising the consumer banking experience with artificial intelligence, Journal of Digital Banking, 4(4), 291-300 (2020)

2. Efma. World retail banking report 2018, https://www.efma.com/study/detail/28603

3. Fintech in Russia Bloomchain. (2019) https://bloomchain.ru/Fintech2019.pdf

4. AI market in Russia, ABBYY Russia. (2019). https://promo.abbyy.com/rs/446-REF821/images/ABBYY\%20IDC\%20Research.pdf)

5. P. Rutten, and D. Schubmehl, Hitting the Wall with Server Infrastructure for Artificial Intelligence. IDC White Paper (2017) https://www.ibm.com/downloads/cas/XBEOJWL5

6. S. Volkov, Banks teach machine, Expert RA (2019) https://www.raexpert.ru/press/articles/bo_volkov_01_2019

7. T. Lau, and B. Leimer, The era of connectedness: How AI will help deliver the future of banking, Journal of Digital Banking, 3(3), 215-231 (2019)

8. F. D'Acunto, N. Prabhala, and A.G. Rossi, The promises and pitfalls of robo-advising, The Review of Financial Studies, 32(5), 1983-2020 (2019) 
9. Sberbank tests chatbot based on AI in Sberbank Markets, CNews (2019) https://www.cnews.ru/news/line/2019-0201_sberbank_nachal_testirovanie_chatbota_na_baze.

10. Koshkina J. Sberbank predicts job termination based on AI, RBC (2019). https://www.rbc.ru/finances/18/10/2019/5da8a01c9a79473da5aff893

11. C. Soviany, AI-powered surveillance for financial markets and transactions, Journal of Digital Banking, 3(4), 319-329 (2019)

12. J.V.D. Burgt, Explainable AI in banking, Journal of Digital Banking, 4(4), 344-350 (2020).

13. AI and business: do they keep in contact? (2019) RPORC https://wciom.ru/index.php?id=236\&uid=10068.

14. Larin I. Russians attitude towards AI (2018). IBM blog. https://www.ibm.com/blogs/ibm-russia/2018/12/russia-ai-survey/.

15. AI: threat or opportunity? (2020) RPORC. №4154. https://wciom.ru/index.php?id=236\&uid=10132.

16. How much will make Sberbank with AI? (2020) https://frankrg.com/12218/.

17. R.S. Deshpande, A study of Adoption of Artificial Intelligence in Banking Sector, UGC Care Journal, 31(13), 61-67 (2020) 